This is a pre-copyedited, author-produced version of an article accepted for publication by

Emerald in International Journal of Sustainability in Higher Education on 2017 following peer

review, available online: https://doi.org/10.1108/IJSHE-04-2015-0069.

Cruz, L.; Barata, E.; Ferreira, J-P.; Freire, F. (2017) "Greening transportation and parking

at University of Coimbra", International Journal of Sustainability in Higher Education, 18(1),

23-38 (https://doi.org/10.1108/IJSHE-04-2015-0069)

\title{
Greening transportation and parking at University of Coimbra
}

Greening
transportation
and parking

\author{
Luís Cruz and Eduardo Barata
}

GEMF and CeBER - Faculty of Economics, University of Coimbra, Coimbra, Portugal

João-Pedro Ferreira

GEMF and CeBER - Faculty of Economics, University of Coimbra, Coimbra, Portugal and MIT-Portugal Program, Energy for Sustainability (EfS) Initiative of the University of Coimbra, Coimbra, Portugal, and

Fausto Freire

ADAI-LAETA, Department of Mechanical Engineering,

University of Coimbra, Coimbra, Portugal

\begin{abstract}
Purpose - This paper aims to explore the potential contribution of integrated traffic and parking management strategies to ensure more rational use of available parking spaces and to reduoe fuel consumption and greenhouse gas emissions by commuters traveling to the University of Coimbra (UC) main campus.

Design/methodology/approach - An integrated modelling approach is used, including the characterization of supply and demand for parking and public transport, the creation and implementation of a survey to campus users and a lifecycle approach to assess six transportation and parking strategy soenarios.

Findings - This comprehensive analysis demonstrates the importance of integrated management measures to greening commuters' transportation and parking within a University campus, identifying and quantifying opportunities for successfully making the transitions toward a more sustainable future, namely, increasing well-being and reducing environmental impact.

Practical implications - Results demonstrate that effective control of illegal parking and different forms of modal shift toward public transportation may contribute to important reductions in environmental impacts. Social implications - Local population reveals willingness to participate in collective efforts to tackle traffic and parking problems, challenging authorities to take action and empowering ever more people to engage in such cathartic changes.

Originality/value - This comprehensive approach is highly valuable for the management of parking and traffic within the UC campus, providing innovative lessons on the social and environmental impacts that would result from this policy approach to urban areas (e.g. historical centers) facing the typical problems of a carbon society, such as traffic congestion, non-regulated parking and intensive car use.
\end{abstract}

Keywords Green campus, Life-Cycle assessment, Sustainable transportation,

Traffic and parking management, Urban transportation

Paper type Research paper

This work has been framed under the Energy for Sustainability Initiative of the University of Coimbra and supported by the R\&D Project EMSURE - Energy and Mobility for Sustainable Regions (CENTRO 070,224 FEDER 002004) and by the Portuguese Foundation for Science and Technology (FCT) through the doctoral grant FCT DFRH SFRH/BD/76357/2011 and the project PTDC/EMS-ENE/1839/2012 (Sustainable mobility: Perspectives for the future of biofuel production).

Recrived 20 Arri 2015 Revised 4 November 2015 5 January 2916 Amepted 5 January 2016 


\section{Introduction}

Transport Demand Management is a critical urban strategy which is mostly applied with the aim of rebalancing the modal split between private car and alternative public transport systems. The management of parking places is often a critical element for changing behaviors by supporting the move from individual/private car use to collective/public transport (see Inci, 2015 for an extensive review on the economics of parking). Parking is thus a key topic in urban transport planning and traffic management (Davis et al., 2010; van Ommeren et al., 2014; Verhoef et al., 1995). Universities are privileged spaces to apply these policies, as commuting can be considered as one of the largest impacts a University campus has on the environment (Alshuwaikhat and Abubakar, 2008) and may represent a noticeable share of urban traffic when the University is located within a city (Rotaris and Daniels, 2015).

Cruising for parking further exacerbates traffic congestion, causes accidents, wastes fuel and other resources, pollutes the air, degrades pedestrian environment and restrains levels of accessibility (Arnott and Rowse, 2009; Kobus et al., 2013; Pitsiava-Latinopoulou et al., 2013), and so contributes to negative impacts on both the local and global environment, depleting natural capital and the quality of life.

The pathway to a transition to a 'post-carbon' society goes beyond energy efficiency technologies alone and requires far-reaching transformation in lifestyles, consumption patterns, and forms of urbanization (Banister, 2007). Further, as Lenzen and Cummins (2011) argued, one major challenge for decision makers to promote such lifestyle changes is to convince the public that, despite some trade-offs, it is possible to achieve sustainability goals with increased well-being and reduced environmental impact.

Going beyond the mainstream traffic and parking management policies, this article explores the importance of integrated parking management policies to ensure a more rational use of the available parking spaces, and to reduce greenhouse gas (GHG) emissions, fossil 
fuel consumption and primary energy requirements by commuters traveling to a major University campus in Portugal: the University of Coimbra (UC) Polo I Campus.

The UC is located on a hill overlooking the city of Coimbra and the River Mondego (see Figure 1), and comprises a cluster of historical buildings which has grown and evolved over more than seven centuries, and which unquestionably constitutes a dignified and well-defined urban area within the city. The historical, cultural, artistic and architectural values of this site were recognized in 2013 when it was granted UNESCO World Heritage status. The need to ensure a balance that does not jeopardize the normal enjoyment and the preservation of these cultural heritage assets presents a tough research agenda. Barata et al. (2011) offered a first important contribution to this endeavor that establishes a solid basis for further analysis of the assessment of integrated parking management policies.

Figure 1 - University of Coimbra and the city of Coimbra, Portugal

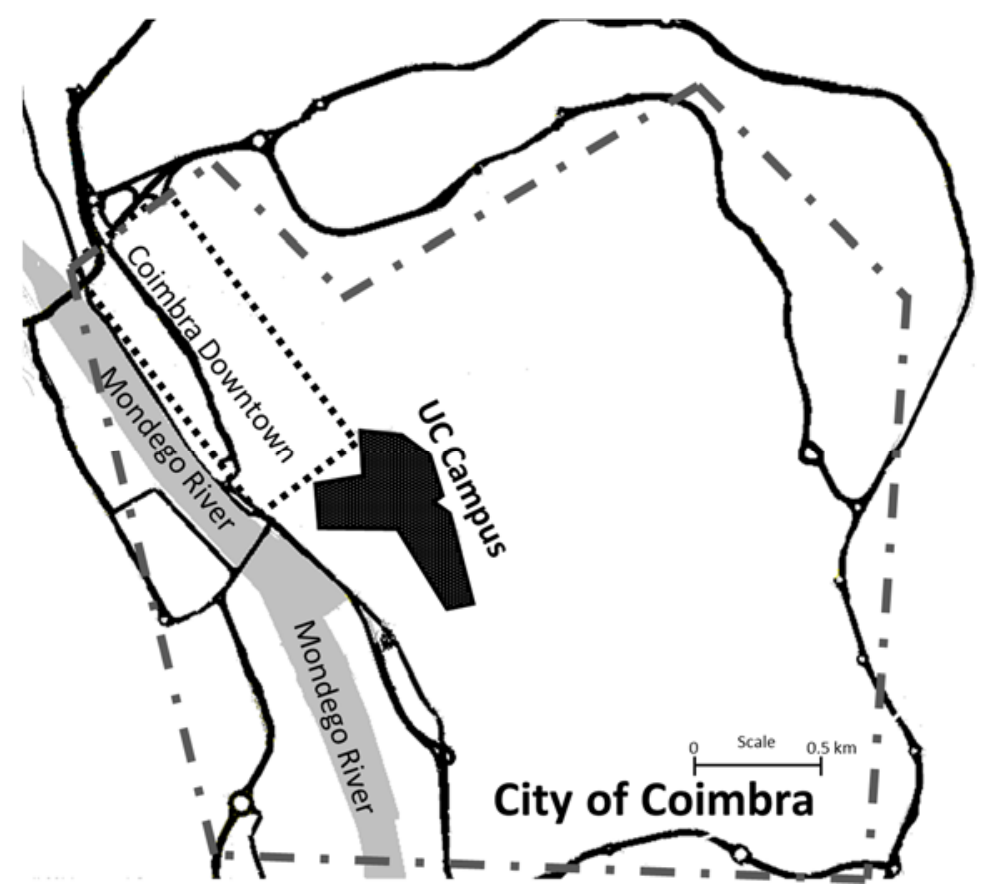

The goal of this article is threefold. First, the quantitative and qualitative analysis of the UC case study should confirm the major significance and the multiple (local and global) impacts from travelling and parking within the campus area. Second, this research examines 
the commuters' willingness to participate in the collective efforts to tackle traffic and parking problems in the campus area. Third, a life cycle approach is used to assess six alternative scenarios covering potential changes in local parking and traffic policies/strategies.

For this, an 'integrated modelling approach' is used, which includes:

- an ad-hoc computation process concerning the parking places available, their location and characteristics;

- the analysis of reports from the local transport authorities and semi-structured interviews of their managers about the analysis of public road transport services, their supply and characteristics;

- the counting of traffic flows to estimate demand;

- the creation and implementation of a survey to characterize commuters and get their responses to potential measures to encourage giving up car use and/or increasing public transport facilities;

- a life-cycle (LC) approach focused on 2 types of impacts: primary energy requirements and GHG emissions.

The analysis is structured as follows. Section 2 provides a quantitative and qualitative analysis of current parking demand and supply, and the use of public transport services within the UC Campus. Section 3 presents the main methodological aspects of the calculations of LC energy requirements and GHG emissions associated with the alternative potential changes in parking and traffic policies. Section 4 concludes.

\section{Supply and Demand for Parking and the use of public transport}

This section characterizes supply and demand for parking at the UC Campus so as to shed light on the different impacts on parking and traffic inside the UC Campus that could occur with the implementation of specific new measures. For this, we analyzed the supply of 
parking places, their location and characteristics. The number of parking places by type and the number of (trolley and diesel) buses that run on the Campus are thus presented in subsection 2.1. Demand characterization requires a more detailed analysis to identify peak congestion periods and the type of parking places preferred by commuters who try to park in this area. The most relevant results for demand characterization and their appraisal against supply are given in sub-section 2.2. Sub-section 2.3 sets out some of the main components of this research survey to allow the socio-economic characterization of UC campus commuters and assess their (actual and potential) travel options. Finally, sub-section 2.4 synthetizes the results of recent parking demand-oriented experiences applied in the context of university campuses.

\subsection{Supply of Parking Places and Public Transport Services}

The results of an ad-hoc computation process of parking places types identified within the study area (see Figure 2, with the geographical location of the controlled parking types) can be found in table 1.

Figure 2 - Controlled parking places location at the UC Campus

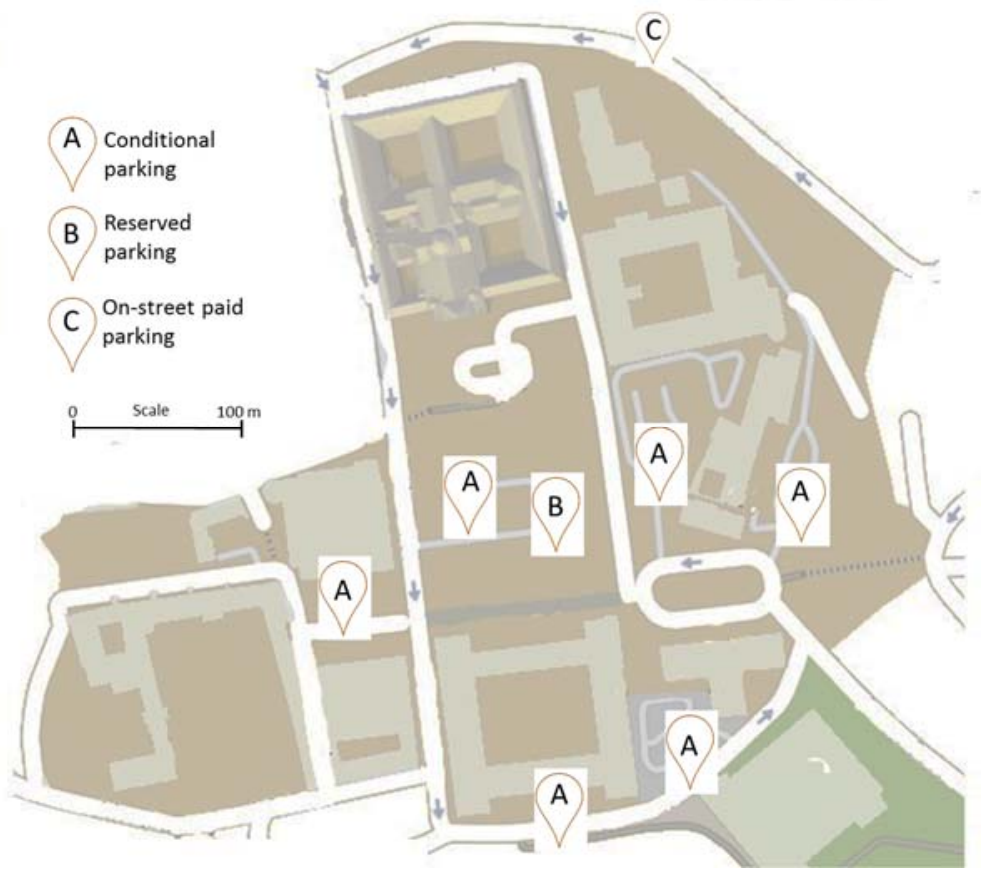


Table 1 - Parking places available at the UC campus

\begin{tabular}{lcc}
\hline Type of parking places & $\begin{array}{c}\text { Number of } \\
\text { places }\end{array}$ & $\begin{array}{c}\text { \% of total } \\
\text { supply }\end{array}$ \\
\hline $\begin{array}{l}\text { Conditional parking access for UC staff }(A) \\
\text { (spread over six sites) }\end{array}$ & 574 & 42.5 \\
$\begin{array}{l}\text { Reserved parking for occasional non-UC staff, and } \\
\text { for people with disabilities (B) }\end{array}$ & 25 & 1.9 \\
On-street paid parking (C) & 132 & 9.8 \\
Free parking (legal) & 484 & 35.8 \\
Non-regular parking & 136 & 10.1 \\
Total & 1351 & 100.0 \\
\hline
\end{tabular}

Table I shows that more than $45 \%$ of the parking places are free (legal and non-regular parking places are spread throughout the Campus, reason why its location is not signaled in Figure 2). Places providing conditional access to UC staff (A) and reserved parking for occasional non-UC staff and for people with disabilities (B) are managed by the university administration. On-street paid parking places (C) are all in Rua Padre António Vieira and are managed by Coimbra City Council.

The supply of road public transport services to the Campus was also estimated. Information available from the local transport authority confirmed that 117 diesel (approximately 80\%) and trolley (approximately 20\%) buses pass through the Campus each day, with an average on-campus journey of $1.7 \mathrm{~km}$ and altogether travelling nearly $149 \mathrm{~km}$ per day. These figures were projected into a full year, taking into account the seasonality in the provision of bus services (distinguishing the periods of the academic year with and without classes).

\subsection{Demand for Parking}

Estimating demand for parking is more complicated than estimating supply. The vehicles that circulate around and park at the Campus are what govern the demand for parking. Accordingly, the empirical approach selected to describe and quantify the parking demand at the UC campus was to count traffic flows. The inflow and outflow of vehicles was computed 
to assess the quantitative dimension of the potential parking problem at the UC Campus. The idea is that the volume of vehicles entering and leaving in conjunction with the average space occupancy rates can be used to evaluate how many vehicles might be benefiting from a specific type of parking space on campus, at a specific moment in time. It is important to mention that different parking options are also associated with different travelling distances within the Campus.

Regarding the demand for the parking sites with conditional access for UC staff, average occupancy rates show that they are not totally saturated, with rates varying from $59 \%$ to $87 \%$ around the six sites. Furthermore, the modelling approach indicates that, on average and on a normal day with classes, the saturation point for each type of space is expected to be achieved as follows: free and legal places by 8:30-8:40 am, non-regular spaces by 9:00-9:10 am, and on-street paid parking by 9:20-9:30 am. Average numbers also indicate that demand gathers pace at around 8:00 am, reaching a peak around 9:00 am, and then declining until 10:00 am.

The counting process was also considered in order to estimate total entry of cars in the UC Campus and associate each car with a specific occupied place and to the path travelled within the Campus (and corresponding distance). It was estimated that approximately 5500 cars enter the Campus every day, travelling approximately 7600 kilometers per day (and nearly 1640000 kilometers per year).

To sum up, comparing the supply and demand estimations, our results indicate that the parking facilities are underpriced and that there is overcrowding. In the early morning, all or nearly all the parking places are occupied, while many drivers continue to enter the Campus searching for something that is almost impossible to find. Moreover, while searching for a space, drivers are consuming fuel, and polluting and mischaracterizing an area of outstanding artistic and architectural value. This conclusion is strengthened by the fact that non-regular parking has actually become a 'valid parking alternative' (inducing even more negative 
externalities). Indeed, it is worth noting that the occupation of non-regular spaces is common, despite the risk of being fined (namely because the current control level of parking at the UC campus is sporadic and drivers tend to perceive that the risk of being fined is low).

\subsection{The Survey}

Taking into account the typical focus of policy authorities worldwide on discouraging the use of private cars and encouraging the use of sustainable modes of transport (Batabyal and Nijkamp 2013), a survey to characterize UC Campus commuters and their answers to potential measures to discourage car use and/or increase public transport use was designed and implemented by the authors.

The survey form comprises a total of 68 variables, organized in two groups that include questions about mobility characteristics and the respondent him/herself. Details on the methods followed and a more comprehensive and detailed analysis of the survey results are explored in Barata et al. (2011). The analysis here integrates survey results and the characterization of supply and demand for parking and public transport with the use of the LCA methodology, thus allowing extending the analysis to the assessment of socioeconomic and environmental impacts of potential transportation and parking strategies. Accordingly, the survey information displayed includes only the elements considered to be directly supportive to delineate the alternative scenarios (covering potential changes in local parking and traffic policies) identified and to be assessed in section 3 .

The survey part with questions about UC campus users' mobility considers issues relating to the number of commuting trips per week, arrival time each day, the frequency of public transport use (previous) and the predominant transport mode. Using a stated preferences approach, respondents moved to a different set of questions, depending on the mode of transport they used most. Those who mostly used a private car were asked, among other things, how much they would be willing to pay for having guaranteed parking on campus (see 
Figure 3). Furthermore, those usually going by car were also asked what amount of the city's urban transport pass free percentage they would regard as 'enough' to make them change to using public transport. The purpose was to study commuters' reaction to potential suggestions for assigning a price to parking (Anastasiadou et al., 2009; Balsas, 2003; Brown et al., 2001; Kadesh and Roach, 1997; Khodaii et al., 2010; Shang et al., 2007; Tolley, 1996; Vadas et al., 2007).

Figure 3 - Willingness to Pay to have guaranteed parking on UC campus ( $€$ per day)

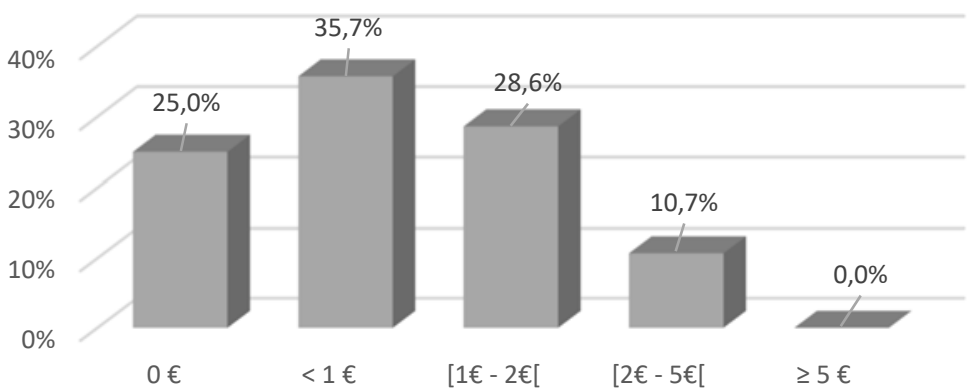

The results in Figure 3 show that none of the drivers would be available to pay more than five euros per day and that only $10.7 \%$ of the drivers declared to be willing to pay more than two euros per day.

Concerning the regularity of commuting to the UC campus, of the sample of 217 individuals, $75.6 \%$ reported making the trip five or more days per week and $14.7 \%$ four days per week. $41.5 \%$ of respondents said that they regularly walk to the UC Campus, $32.3 \%$ drive (of whom, $82.9 \%$ drive their own car, and $42.9 \%$ travel alone), and $25.3 \%$ stated that they regularly take public transport. However, when asked if they had ever used a public transport alternative in the previous month (even if this option is not the most frequent one), the majority (51.2\%) answered positively. 
Those who mainly use cars were also asked to indicate their satisfaction level with parking amenities and the flow of traffic within the campus. Most of them (52.2\%) reported being very dissatisfied with the availability of parking, and 40\% were dissatisfied with traffic flow. A similar question was asked only of respondents who indicated that they mostly use public transport. Half of these individuals gave a positive evaluation of the public transport service, and only $25.9 \%$ were dissatisfied. The disparity between the levels of satisfaction for these two groups of respondents also suggests there is significant welfare loss associated with travelling to the Campus by car.

Concerning 10 statements about potential measures that could lead to an individual increasing public transport use, $87.7 \%$ of the car drivers declared that they would be receptive to using public transport if waiting time was reduced, $79.7 \%$ stressed the role of increasing public transportation feasibility and $77.1 \%$ considered a reduction in travel time as critical. Improving comfort was mentioned by $63 \%$ of the respondents. Finally, only $4.4 \%$ of the drivers said that they would not stop using a car in favor of public transport in any circumstances. Car drivers were also invited to reply to several questions about whether they would accept compensation in return for a modal change to public transport. One question concerned the minimum percentage of the pass for unlimited access to public transport that they would be prepared to accept in order to change from commuting to the Campus by car (see Figure 4). 
Figure 4 - Willingness to Accept compensation to change to public transport (\% of the bus pass fare)

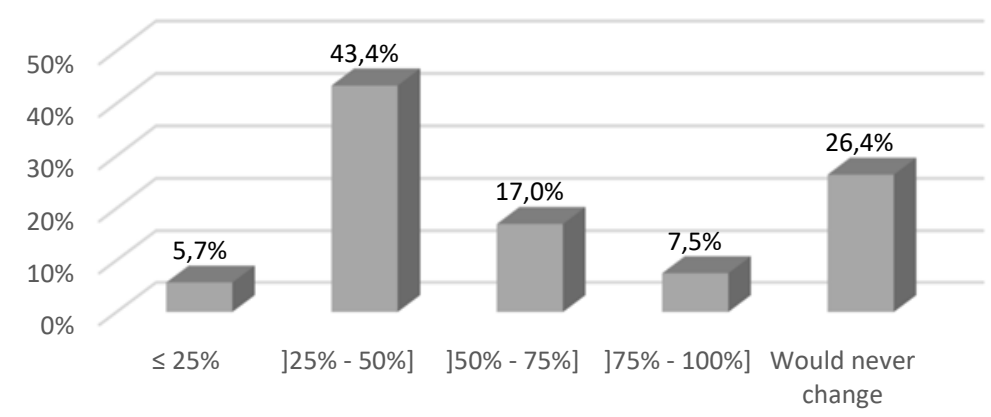

Surprisingly, $49.1 \%$ were prepared to accept compensation equivalent to $50 \%$ of its cost, and only $26.4 \%$ said that this remedy would be totally rejected by them, irrespective of the subsidy.

Accordingly, the analysis demonstrates that decreasing the parking subsidy would not only make car driving (relatively) less attractive, but it could also constitute an important source of revenue by encouraging drivers to use public transport. Indeed, an important number $(73.6 \%)$ of car drivers showed a positive Willingness to Accept compensation to use public transport.

\subsection{Parking policies in the context of university campuses}

Though the application of parking demand-oriented policies may be subject to local specifications and constrains, several experiences with university campuses throughout the world have been highlighting the universal potentiality of these policy approaches. Shannon et al. (2006) find that subsidizing public transport services while increasing the cost of parking is the most promising policy mix to induce a modal change at the University of Western Australia. Brockman and Fox (2011) find that the share of staff members commuting by car dropped from $50 \%$ in 1998 to $33 \%$ in 2007 , after the application of several Transport Demand Management measures (some of them directed towards parking costs increase). Tezcan (2012), with the case of the Istanbul Technical University, demonstrates that 
significant switches to mass transit modes can be sustained if parking pricing is introduced. Similarly, Zhou (2014) concludes that the implementation of a public transport fare-free pilot study at the University of California led to a $20 \%$ decrease in campus parking by solo drivers. Rotaris and Danielis (2015) test 9 hypothetical transport policies at the University of Trieste, in Italy, and highlight three policies that lead to a decrease in car use and are also considered as social and economic efficient: subsidizing bus fares, a mix of bus subsidies with parking restrictions and both parking prices and restrictions. To sum up, it is possible to argue that these studies, related to commuters behavior in the context of university campuses, reveal results that compare well with ours, therefore reinforcing the argument that the adoption of policies to induce a change in the modal split of car drivers are critical to persuade university staff and students to have more sustainable commuting practices. This is the why the survey information offered in this section is particularly concentrated on the analysis of the results based on the Willingness to Pay (for parking places) and Willingness to Accept (compensation for changing to public transport) concepts in order to help delineating the scenarios to be assessed in the following section.

\section{Measuring environmental impacts of changes in commuters' modal}

\section{split}

The methodology used to calculate the life-cycle impacts associated with the alternative scenarios covering potential changes in parking and traffic policies is presented in this section. The basis for setting six specific scenarios, as well as the corresponding estimated changes in final fuel and electricity consumption by passenger cars and buses, life-cycle energy requirements and greenhouse gas (GHG) emissions, are also presented here. 


\subsection{Methodology: Life-cycle energy requirements and greenhouse gas emissions}

A LC approach was used to calculate the overall impacts associated with alternative parking and traffic scenarios. The approach offers a comprehensive picture of the flows of energy and materials through a system and gives a holistic and objective basis for comparison between various alternative scenarios (Malça and Freire, 2010). The most well-known LC approach or tool is life-cycle assessment (LCA) which has been standardized by the International Organization for Standardization (ISO), resulting in the ISO 14040 series: ISO 14040 (ISO 2006a) and ISO 14044 (ISO 2006b). LCA is based on systems analysis and treats the product process chain as a sequence of sub-systems that exchange inputs and outputs. The results of an LCA quantify the potential environmental impacts of a product system over the life-cycle, help to identify opportunities for improvement and indicate more sustainable options where a comparison is made. The LCA methodology consists of four major steps (ISO 14044, 2006a): definition of the goal and scope; life-cycle inventory (LCI); life-cycle impact assessment (LCIA) and interpretation.

The definition of the goal and scope establishes the intended application of the study, including the definition of the product system, system boundary, main assumptions and limitations of the study. In the LCI phase, data is collected to quantify inputs (energy, raw and ancillary materials) and outputs (products, emissions and waste). LCIA calculates environmental impacts by associating LCI data into a set of specific environmental categories and indicators. The interpretation phase involves drawing the main conclusions (consistent with the defined goal and scope), making recommendations and identifying the main limitations of the LCA study. A fundamental characteristic of the LCA methodology is its holistic approach. LCA integrates, into a single framework, direct and indirect environmental impacts of a product chain, avoiding environmental problem shifting (i.e. shifting impacts between environmental media, regions, or life cycle stages). 
As shown in Figure 5, LCA follows an iterative approach, which implies that as new information is collected, adjustments in the scope or inventory may be necessary to improve the comprehensiveness and consistency of the LCA study and reported results.

Figure 5 - Stages of Life Cycle Assessment (ISO 2006a)

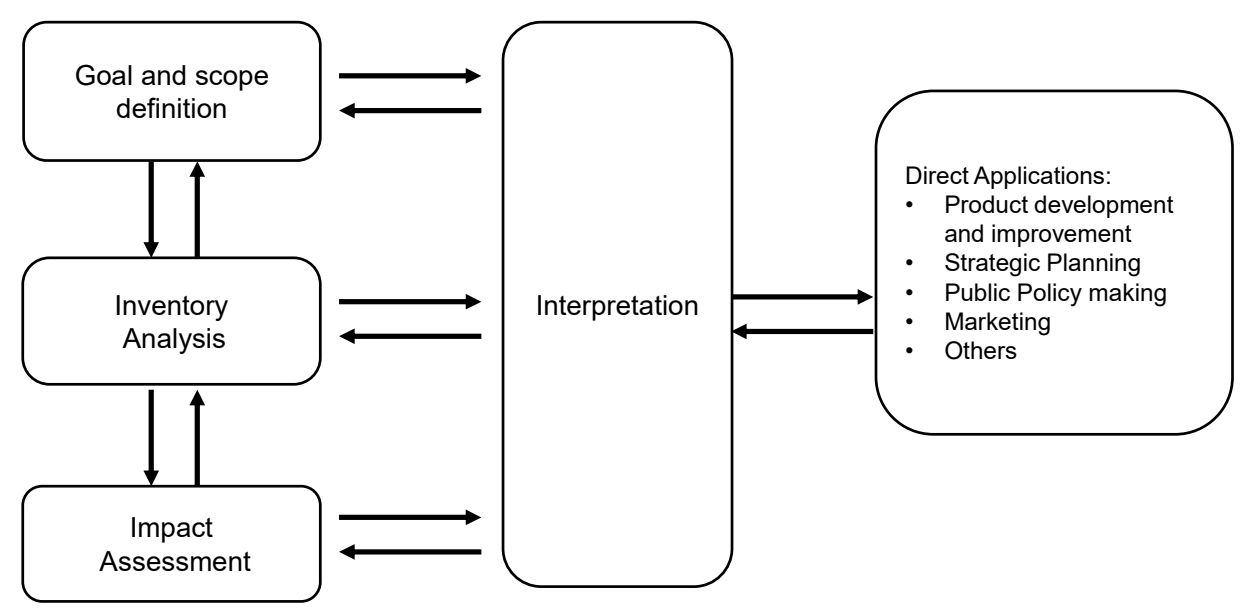

The calculations performed in this research and presented in this section followed the LCA methodology but focus on 2 types of LC impacts: primary energy, and GHG emissions. Primary energy is the sum of the final energy with all the transformation losses, with fuel primary energy values being greater than its final energy values. In fact, consumers buy final energy, but what is really consumed is primary energy, which represents the cumulative energy content of all resources (renewable and non-renewable) extracted from the environment. Table 2 summarizes the final energy (fuel/electricity) consumption required by the various types of transport vehicles.

Table 2 - Final vehicle energy consumption

\begin{tabular}{ccc}
\hline Vehicle & Fuel/electricity & Units \\
\hline Diesel car & 6.6 & $\mathrm{~L} / 100 \mathrm{~km}$ \\
Petrol car & 8.1 & $\mathrm{~L} / 100 \mathrm{~km}$ \\
Electric car & 16.0 & $\mathrm{kWh} / 100 \mathrm{~km}$ \\
Diesel bus & 51.2 & $\mathrm{~L} / 100 \mathrm{~km}$ \\
Electric bus & 300.0 & $\mathrm{kWh} / 100 \mathrm{~km}$ \\
\hline
\end{tabular}


Diesel and trolley bus fuel consumption was calculated from actual annual fleet consumption data provided by the city's bus company (SMTUC, 2010). Data for the electric passenger car was estimated based on Freire and Marques (2012), Marques et al. (2013) and Garcia et al. (2014). Consumption data for diesel and petrol cars was based on European fleet average data (Spielmann et al., 2007).

Life-cycle GHG emissions were calculated by adding together the GHG emissions of the LC stages, namely, vehicle and infrastructure production, fuel production and/or electricity generation and, last but not least, the transportation process itself through fuel combustion (in the case of vehicles with internal combustion engines). A number of GHGs have been considered in the calculations, but tqhe most important are carbon dioxide $\left(\mathrm{CO}_{2}\right)$ followed by methane $\left(\mathrm{CH}_{4}\right)$ and nitrous oxide $\left(\mathrm{N}_{2} \mathrm{O}\right)$, with average global warming potential (GWP) of 25 for $\mathrm{CH}_{4}$ and 298 for $\mathrm{N}_{2} \mathrm{O}$, over a 100 -year time horizon. The global warming potential used by the IPCC provide ' $\mathrm{CO}_{2}$ equivalence' factors for greenhouse gases other than $\mathrm{CO}_{2}$, which allows aggregation of emissions of different gases into a single metric (IPCC, 2007). Finally, the GHG emissions of the overall transportation scenario can be calculated for the scenarios presented in the next sub-section, relative to the business as usual (BAU) situation. The calculations were performed based on the total number of kilometers driven per transport mode associated with each scenario. The methodology adopted in this article can be applied to other University campuses worldwide or other type of applications. Additionally, the methodology can be further extended to address costs or integrated with partial economic models (e.g. Freire et al., 2001).

\subsection{Scenarios}

This sub-section presents the main assumptions considered to establish several scenarios for potential changes in parking and traffic policies, which are focused on producing modifications in commuters' behavior (i.e., changes in the modal split favoring the use of 
public transport). Indeed, changes in the number of cars crossing the Campus, as well as in students and workers modal choices, influence the environmental impacts of transport on the site and worldwide.

The energy consumption estimated for each scenario can be considered as a composite measure of travel distance, modal choice and journey frequency (Muñiz and Galindo, 2005). The counting procedures explained in section 2 were used to estimate the total kilometers per year travelled by cars and (trolley and diesel) buses within the UC Campus. This provided the BAU scenario. Then six different scenarios were derived, based on the hypothetical application of different parking and traffic policies. Before detailing each scenario it is worth noting that all of them assume an increase in public transport efficiency. Indeed, it is considered that the observed average occupation rate (32\%) of the buses that serve the Campus could rise to $70 \%$ without having to bring additional buses to the Campus. In other words, the reductions in the use of cars (and taking into account the observed average occupancy rate of 1.2) to travel to the Campus considered in the scenarios, are 'compensated' by a corresponding increase in the number of bus passengers, which will result in a greater number of buses travelling through the Campus only when the occupation rate exceeds $70 \%$ if the number of buses is unchanged.

The first scenario considers that the effective control of illegal parking banishes this practice and helps to reduce the number of cars in the Campus area by approximately $10 \%$. The corresponding growth in the number of bus passengers would be completely absorbed by existing buses (with an occupancy rate below 70\%).

The second scenario considers banishing all the parking places except the conditional parking access for UC staff. This would result both in a decrease of approximately $55 \%$ in the number of cars and in an increase of one bus per day travelling in the Campus. 
The third scenario is similar to the previous one, except that all the diesel buses travelling in the Campus would be replaced by electric ones.

The fourth scenario considers a new traffic policy that would only allow electric vehicles (either private or public) in the UC campus. Further, it is assumed that in the near future electric cars can represent nearly $5 \%$ of the present number of cars. In terms of public transport, these hypotheses would require increasing the number of (electric) buses travelling in the Campus to 44 buses per day.

The two last scenarios consider a less restrictive traffic policy than the one in the previous scenario, in that while only electric buses would be allowed to circulate in the UC campus, diesel or petrol cars would be permitted. The distinctive additional factors in each of these scenarios result specifically from the survey analysis and involve the application of the Willingness to Pay and Willingness to Accept concepts.

Thus, the fifth scenario considers drivers' reaction to the introduction of a parking charge of two euros per day for each space on the Campus. Indeed, according to the survey results, only $11 \%$ of the drivers would pay more than two euros per day to park on the Campus. Thus it is assumed that $89 \%$ of the drivers would stop driving to the Campus, implying the need to reinforce the provision of (electric) public transport by 38 extra buses a day.

The sixth scenario reflects drivers' answers concerning the Willingness to Accept concept. In the survey, drivers were asked about the amount of the city's urban transport pass free percentage that they would be prepared to accept in order to consider a modal change in favor of public transport services. Thus, as $73.6 \%$ of the drivers stated that they would be willing to take the decisive step of changing to public transport if the cost was reduced, it is considered that all of them would stop using their cars if the University or the City Council impose any kind of policy that would result in a reduction of the public transport cost borne by UC 
campus commuters. Furthermore, in order to accommodate this modal change, the supply of public transport to the Campus would have to increase by 20 buses per day.

\subsection{Results: estimated environmental impacts}

Table 3 presents the results for the six scenarios in terms of total $k m$ driven by each mode of transport: fuel and electric cars; diesel and electric buses. The variation relative to the BAU situation is also presented (Diff. BAU). Scenario 4 offers the most significant decrease in terms of fuel car use on the Campus. However, it should be noted that this is the only scenario where the existence of electric cars is considered, and it also has the most significant use of electric buses. Scenario 5 follows as the best alternative for reducing car use, suggesting that charging for parking can effectively help to cut the number of cars in the Campus.

Table 3 - Total $\mathrm{km}$ driven by transport mode in the six scenarios

\begin{tabular}{|c|c|c|c|c|c|}
\hline & & Fuel Cars & $\begin{array}{l}\text { Diesel } \\
\text { Buses }\end{array}$ & $\begin{array}{l}\text { Electric } \\
\text { Buses }\end{array}$ & $\begin{array}{c}\text { Electric } \\
\text { Cars }\end{array}$ \\
\hline BAU & & 1640000 & 25500 & 6400 & - \\
\hline \multirow{2}{*}{ Scenario 1} & Value & 1474852 & 25500 & 6400 & -- \\
\hline & Diff. BAU & -165148 & -- & -- & -- \\
\hline \multirow{2}{*}{ Scenario 2} & Value & 727012 & 25718 & 6455 & -- \\
\hline & Diff. BAU & -912988 & 218 & 55 & -- \\
\hline \multirow{2}{*}{ Scenario 3} & Value & 727012 & -- & 32391 & -- \\
\hline & Diff. BAU & -912988 & -25500 & 25991 & -- \\
\hline \multirow{2}{*}{ Scenario 4} & Value & -- & -- & 44176 & 82000 \\
\hline & Diff. BAU & -1640000 & -25500 & 37776 & 82000 \\
\hline \multirow{2}{*}{ Scenario 5} & Value & 175480 & -- & 42399 & -- \\
\hline & Diff. BAU & -1464520 & -25500 & 35999 & -- \\
\hline \multirow{2}{*}{ Scenario 6} & Value & 436240 & -- & 37441 & -- \\
\hline & Diff. BAU & -1203760 & -25500 & 31041 & -- \\
\hline
\end{tabular}

Considering the total $\mathrm{km}$ driven presented in table III and following the methodology presented, final electricity and fuel required have been calculated, as well as the primary energy consumption and LC GHG emissions, as presented in table 4. 
Table 4 - Energy Consumption and LC GHG Emissions

\begin{tabular}{|c|c|c|c|c|}
\hline & $\begin{array}{c}\text { Electricity } \\
\text { consumption } \\
(\mathrm{kWh})\end{array}$ & $\begin{array}{c}\text { Fuel } \\
\text { (Liters) }\end{array}$ & $\begin{array}{c}\text { Primary } \\
\text { Energy } \\
(\mathrm{MJ})\end{array}$ & $\begin{array}{c}\mathrm{LC} \mathrm{GHG} \\
\text { Emissions } \\
\left(\mathrm{kg} \mathrm{CO}_{2} \mathrm{eq}\right)\end{array}$ \\
\hline BAU & 19456 & 133809 & 5695718 & 501718 \\
\hline Scenario 1 & $0.0 \%$ & $-9.1 \%$ & $-8.8 \%$ & $-9.1 \%$ \\
\hline Scenario 2 & $0.9 \%$ & $-50.2 \%$ & $-48.3 \%$ & $-50.3 \%$ \\
\hline Scenario 3 & $406.1 \%$ & $-60.0 \%$ & $-45.8 \%$ & $-49.5 \%$ \\
\hline Scenario 4 & $656.1 \%$ & $-100.0 \%$ & $-76.7 \%$ & $-83.7 \%$ \\
\hline Scenario 5 & $562.5 \%$ & $-90.3 \%$ & $-70.3 \%$ & $-76.8 \%$ \\
\hline Scenario 6 & $485.0 \%$ & $-76.0 \%$ & $-58.9 \%$ & $-64.0 \%$ \\
\hline
\end{tabular}

The results show that scenarios 4, 5 and 6 provide significant reductions in LC GHG emissions due to important reduction in fossil fuel energy consumption as well as the technological change to electric buses (and to electric cars in Scenario 4).

The results for Scenario 1 show that if local authorities really did control illegal parking it would have significant effects, not only in terms of fairness, but also in terms of the quality of life associated with both the reduction in GHG emissions and the freeing up of more and better pedestrian areas (as non-regular parking occurs predominantly in pedestrian walking zones). Scenario 2 suggests that restricting private car use on the Campus to those who have access to UC staff parking would cut primary energy consumption and GHG emissions to nearly half the current levels. Scenario 3, where diesel buses are 'replaced' by electric ones, leads to savings in primary energy consumption and GHG emissions that are almost as important as those provided under Scenario 2 conditions.

Scenario 4 has the most extreme conditions, where only electric vehicles can circulate, and it is the scenario in which parking and traffic management is more efficient regarding (final and primary) energy consumption and GHG emissions. Indeed, the results underscore the positive environmental impacts of substituting the intensive use of cars with well-organized public transport services.

Additionally, as in the previous scenario, the estimations for Scenarios 5 and 6 show that properly enforced parking policies could also contribute to important reductions in energy 
consumption and GHG Emissions. Charging for parking and changing the transportation mode used within the Campus could play a significant part in a much more environmentally sustainable solution. In addition, it would generate new revenues that can be allocated to making improvements in the service provided by the local public transport authority (Shoup, 2004). Indeed, the results indicate that simply introducing a parking charge of 2 euros per day has the potential to reduce GHG emissions by more than $75 \%$, while subsidizing the public transport pass could help to reduce GHG emissions by $64 \%$. This certainly reinforces the importance of raising environmental awareness within campus communities (Dahle and Neumayer, 2001) and of proper communication of the purpose and effects of such a parking charge policy. It should be advocated as a justifiable policy rather than as a measure primarily to address congestion, though simultaneously pursuing other objectives such as preservation of the environment and of this outstanding cultural and architectural heritage. It must be made quite clear that the revenues raised will be used to reduce the price of public transport.

\section{Conclusions}

This study has explored the potential contribution of integrated parking management policies: (i) to ensure more rational use of the available parking spaces, and (ii) to reduce greenhouse gas (GHG) emissions, fossil fuel consumption and primary energy requirement by commuters to the UC Campus.

The area studied is the UC Campus, considered by UNESCO to have outstanding cultural, artistic and architectural value, where approximately $45 \%$ of the parking places are free and without any kind of access restrictions. Further, the analysis showed that there are a significant number of illegal parking places being used every day. This conclusion is especially worrying considering that Universities have the potential to influence the students' current mobility choices, their environmental awareness and the habits they can develop in the 
long term (Finlay and Massey, 2012), that is, they can become powerful forces in reshaping society's future transportation patterns (Barata et al., 2011).

The life cycle assessment of six alternative scenarios covering potential changes in local parking and traffic policies/strategies allowed the identification (and quantification) of opportunities for successfully making the transitions required to attain double dividends towards a more sustainable future, namely increased (local) well-being and reduced (local and global) environmental impacts. It has been demonstrated that a policy measure as simple as controlling illegal parking may result in a nearly $10 \%$ fall in GHG emissions generated on the Campus. Furthermore, different forms of modal shift from private cars to public transport (that is to buses) are critical to significantly reduce overall environmental impacts. Another noteworthy conclusion is that the introduction of a parking charge may lead to an overall reduction in GHG emissions of more than $75 \%$. Moreover, these revenues can be used by the University administration and/or local authority to subsidize the price of the public transport pass and/or to improve the quality of the service, thereby helping to lower the resistance to decreasing the use of private cars. Certainly, the implementation of coordinated solutions that would let people park farther from the University and use bus services to carry them comfortably on feasible routes to anywhere on the Campus, is a strategy that the local transport authority and the University administration should consider.

Additionally, given that 'public acceptability drives political acceptability' (Banister, 2008: 76), one of the most interesting outcomes of this comprehensive analysis is the commuters' willingness to participate in the collective efforts to tackle traffic and parking problems in the campus area. In other words, if commuters' current behavior is part of the problem, it is clear that there is an important predisposition on their part to become part of the solution for greening transportation and parking at the UC Campus, thus challenging the authorities to take action by adopting the necessary improvement measures. Indeed, the authorities now 
have the opportunity to take advantage of the recent UNESCO decision that the University of Coimbra has unquestionable exceptional universal value, and encourage participation of the local population in the preservation of this world cultural and natural heritage site, increasing their own well-being and simultaneously contributing to reduce negative impacts on the global environment.

Finally, this innovative integrated modelling approach considers the effective potential of combined traffic and parking management measures to greening commuter transportation and parking in urban areas and empowers more and more people to engage in such transformative changes locally, regionally, nationally and globally. Throughout the world, universities administrations are becoming increasingly concerned with car ill effects, while also applying measures designed to create a sustainable campus environment (Paéz and Whalen, 2010). Indeed, 'big universities resemble small cities' (Shoup, 2008: 147), and interventions in traffic and parking demand management at university campuses provide important lessons on the (positive) social and environmental impacts that would result from the transfer of this policy approach (as argued in Marsden et al., 2011) to urban areas (for example historical centers) that face the typical problems of a carbon society, such as traffic congestion, nonregulated parking and intensive car use.

\section{Acknowledgments}

This work has been framed under the Energy for Sustainability Initiative of the University of Coimbra and supported by the R\&D Project EMSURE - Energy and Mobility for Sustainable Regions (CENTRO 070224 FEDER 002004) and by the Portuguese Foundation for Science and Technology (FCT) through the doctoral grant FCT DFRH SFRH/BD/76357/2011 and the project PTDC/EMS-ENE/1839/2012 (Sustainable mobility: Perspectives for the future of biofuel production). 


\section{References}

Alshuwaikhat, H. and Abubakar, I. (2008), “An integrated approach to achieving campus sustainability: assessment of the current campus environmental management practices", Journal of Cleaner Production, 16(16), 1777-1785.

Anastasiadou, M., Simitriou, D., Fredianakis, A., Lagoudakis, E., Traxanatzi, G. and Tsagarakis, P. (2009), "Determining the parking fee using the contingent valuation methodology", Journal of Urban Planning and Development, 135(3), 116-124.

Arnott, R. and Rowse, J. (2009), “Downtown parking in auto city”, Regional Science and Urban Economics, 39(1), 1-14.

Balsas, C. (2003), "Sustainable transportation planning on college campuses", Transport Policy, 10(1), 35-49.

Banister, D. (2008), “The sustainable mobility paradigm”, Transport Policy, 15(2), 73-80.

Banister, D. (2007), "Cities, mobility and climate change”, Journal of Industrial Ecology, 11(2), 9-11.

Barata, E., Cruz, L. and Ferreira, J.-P. (2011), "Parking at the UC Campus: Problems and Solutions", Cities 28(5), 406-413.

Batabyal, A. and Nijkamp, P. (2013), “Ought a green citizen to bicycle or take public transport to work?”, Ecological Economics, 86, 93-96.

Brockman, R. and Fox, K. (2011), "Physical activity by stealth? The potential health benefits of a workplace transport plan”, Public Health, 125, 210-216.

Brown, J., Hess, D. and Shoup, D. (2001), “Unlimited access”, Transportation, 28, 233-267. 
Davis, A., Pijanowski, B., Robinson, K. and Engel, B. (2010), "The environmental and economic costs of sprawling parking lots in the United States", Land Use Policy, 27(2), $255-261$.

Dahle, M. and Neumayer, E. (2001), “Overcoming barriers to campus greening: A survey among higher educational institutions in London, UK”, International Journal of Sustainability in Higher Education, 2(2), 139-160.

Finlay, J., and Massey, J. (2012), "Eco-campus: applying the ecocity model to develop green university and college campuses", International Journal of Sustainability in Higher Education, 13(2), 150-165.

Freire, F. and Marques, P. (2012), "Electric Vehicles in Portugal: an integrated energy, greenhouse gas and costs life-cycle analysis", in Proceedings of the 2012 IEEE ISSST International Symposium on Sustainable Systems and Technology, 6 p, Boston.

Freire, F., Thore, S. and Ferrão, P. (2001), "Life cycle activity analysis: logistics and environmental policies for bottled water in Portugal”, OR Spektrum, 23(1), 159-182.

Garcia, R., Marques, P. and Freire, F. (2014), "Life-cycle assessment of electricity in Portugal”, Journal of Applied Energy, 134, 563-572.

Inci, E. (2015), "A review of the economics of parking", Economics of Transportation, 4, $50-63$.

IPCC (2007), Climate Change 2007 - The Physical Science Basis, Fourth Assessment Report, IPCC (Intergovernmental Panel on Climate Change), New York: Cambridge University Press.

ISO (2006a), ISO 14040: Environmental management - life cycle assessment - principles and framework, Geneve: International Organization for Standardization. 
ISO (2006b), ISO 14044: Environmental management - life cycle assessment - requirements and guidelines, Geneve: International Organization for Standardization.

Kadesh, E. and Roach, W. (1997), “Commute trip reduction — a collaborative approach”, Energy Policy, 25(14-15), 1217-1225.

Kaplan, D. (2015), “Transportation sustainability on a university campus", International Journal of Sustainability in Higher Education, 16(2), 173-186.

Khodaii, A., Aflaki, E. and Moradkhani, A. (2010), "Modeling the effect of parking fare on personal car use”, Scientia Iranica - Transaction A: Civil Engineering, 17(3), 209-216.

Kobus, M., Gutiérrez-i-Puigarnau, E., Rietveld, P. and Van Ommeren, J. (2013) “The on-street parking premium and car drivers' choice between street and garage parking”, Regional Science and Urban Economics, 43(2), 395-403.

Lenzen, M. and Cummins, R. (2011), "Lifestyles and well-being versus the environment", Journal of Industrial Ecology, 15(5), 650-652.

Malça, J. and Freire, F. (2010), "Uncertainty Analysis in Biofuel Systems: An Application to the Life Cycle of Rapeseed Oil”, Journal of Industrial Ecology, 14(2), 322-334.

Marques, P., Garcia, R. and Freire, F. (2013), Life cycle assessment of electric and conventional cars in Portugal, in Energy for Sustainability 2013 - Sustainable Cities: Designing for People and the Planet Conference Proceedings 1, Coimbra, Portugal.

Marsden, G., Frick, K., May, A. and Deakin, F. (2011), "How do cities approach policy innovation and policy learning? A study of 30 policies in Northern Europe and North America," Transport Policy, 18, 501-512.

Muñiz, I. and Galindo, A. (2005), "Urban form and the ecological footprint of commuting: The case of Barcelona”, Ecological Economics, 55(4), 499-514. 
Paéz, A. and Whalen, K. (2010), "Enjoyment of commute: a comparison of different transportation modes", Transportation Research Part A: Policy Practice, 44(7), 537-549.

Pitsiava-Latinopoulou, M., Basbas, S. and Gavanas, N. (2013), "Implementation of alternative transport networks in university campuses: The case of the Aristotle University of Thessaloniki, Greece”, International Journal of Sustainability in Higher Education, $14(3), 310-323$.

Rotaris, L. and Daniels, R. (2015), "Commuting to college: The effectiveness and social efficiency of transportation demand management policies", Transport Policy, 44, $158-168$.

Shang, H., Lin, W. and Huang, H. (2007), "Empirical Study of Parking Problem on University Campus", Journal of Transportation Systems Engineering and Information Technology, $7(2), 135-140$.

Shannon, T., Giles-Corti, B., Pikora, T., Bulsara, M., Shilton, T. and Bull, F. (2006) “Active commuting in a university setting: assessing commuting habits and potential for modal change", Transport Policy, 13, 240-253.

Shoup, D. (2008), “The Politics and Economics of Parking on Campus”, in Ison, S. and Rye, T. (eds.), Transport Demand Management Measures: An International Perspective, Ashgate, 121-149.

SMTUC (2010), Relatório de Gestão e Documentos Financeiros [Management report and financial statements], SMTUC, Coimbra, Portugal.

Spielmann, M., Dones, R. and Bauer, C. (2007), Life Cycle Inventories of Transport Services, Final report ecoinvent v2.0 No. 14. Dbendorf, CH: Swiss Centre for Life Cycle Inventories. 
Tezcan, H. (2012), "Using parking pricing as a travel demand management tool at a university campus: an example for Istanbul Technical University", Transportation Letters: International Journal of Transportation Research, 4, 181-192.

Tolley, R. (1996), “Green campuses: cutting the environmental cost of commuting”, Journal of Transport Geography, 4(3), 213-217.

van Ommeren, J., Groote, J. and Mingardo, G. (2014), “Residential parking permits and parking supply", Regional Science and Urban Economics, 45, 33-44.

Vadas, T., Fahey, T., Sherman, R. and Kay, D. (2007), "Local-scale analysis of carbon mitigation strategies: Tompkins County, New York, USA”, Energy Policy, 35(11), $5515-5525$.

Verhoef, E., Nijkamp, P. and Rietveld, P. (1995), “The economics of regulatory parking policies: The (IM)possibilities of parking policies in traffic regulation", Transportation Research Part A: Policy and Practice, 29(2), 141-156.

Zhou, J. (2014) "From better understanding to proactive actions: housing location and commuting mode choices among university students", Transport Policy, 33, 166-175. 